\title{
Reform Measures for Cultivation Mode of Application-oriented Talents Majoring in Music in Local Undergraduate Universities
}

\author{
Cheng $\mathrm{Xu}^{1}$, Jing $\mathrm{Liu}^{1}$ \\ ${ }^{1}$ XingTai University, Xingtai, 054001, China
}

\begin{abstract}
Keywords: Local undergraduate universities, Music Major, Application-oriented talents, Cultivation mode, Reform
\end{abstract}

\begin{abstract}
The art of music is an important strategy to facilitate the cultural development, symbolizes the cultural soft power of a nation, and plays an irreplaceable role in the current musical culture. Therefore, local undergraduate universities shall pay attention to reforming the cultivation mode of application-oriented talents majoring in music, strive for cultivating new-type music talents for the society, and make a contribution to the construction of socialist culture with Chinese characteristics. Based on this, this paper mainly discusses the reform measures for cultivation mode of application-oriented talents majoring in music in local undergraduate universities.
\end{abstract}

\section{Introduction}

With the continuous development of higher education in our country in recent years, a growing number of students have an increasingly strong desire of receiving the higher education; besides, the rapid development of the social economy urges the higher education system in our country to have corresponding changes to adapt to the development requirements of the contemporary era; concretely, the great-leap-forward development is requirement in both scale and quantity. The previous elite education mode has gradually transformed to the public education mode, and the emergence of application-oriented undergraduate education has favorably adapted to the development needs of the new era. The teaching quality of higher education is closely related to the music education level of elementary and secondary schools and the enhancement of the national music quality; therefore, how to cultivate students' innovation and practice abilities in the music teaching mode has been a very hot topic in the contemporary music field.

\section{Main problems in cultivation mode of talents majoring in music in local undergraduate universities}

\section{Indefinite objectives of music talent cultivation}

Local undergraduate universities occupy an important position in inheriting the musical culture, play different roles in this aspect, are obliged to educate contemporary university students' understanding of inheriting the musical culture, and shall actively take certain measures to stimulate students' potentials in musical culture with traditional features, so as to make them be a new generation of successors of traditional ethnic musical culture. The biggest music education related challenge encountered by local universities of current stage is the lack of definite objectives and a clear talent cultivation mode, which makes the contemporary music talent cultivation unable to meet various requirements of local social and economic development.

\section{Lack of music teaching curriculums and sound relevant systems}

It can be seen from the curriculum arrangement of music majors in local universities that it has exaggerated the essential attributes of music curriculums, overemphasized the systematicness and integrity of a single curriculum, ignored the effective fusion between different curriculums, greatly enhanced the learning difficulty of a single curriculum, and consequently prevented students from receiving more comprehensive knowledge and from obtaining the ability to adapt to the society. Besides, the contents and knowledge in textbooks used in the teaching process are old and rigid, and cannot meet contemporary requirements on music curriculums. 


\section{No regard to organic combination of theoretical music knowledge and practice}

The main tasks of musicology major in local universities are to provide elementary and secondary schools with qualified music teachers and provide new-type talents who are capable of timely completing teaching researches and corresponding management of cultural organizations as well as other tasks; while the music performance major is mainly to cultivate professional playing and singing talents and musical tutorship talents. These tasks require local undergraduate musical universities to pay attention to organic combination of professional theories and practice in the whole process of musical teaching, so aso to really implement the new talent cultivation mode, meet relevant requirements of professional education and teaching systems, and serve the development of local social economy. However, most local undergraduate universities have currently ignored this point.

\section{Linear decrease of specialty teaching quality due to increase in recruit number}

In recent years, almost all the universities in our country are implementing the enrollment expansion plan, which has induced the emergence of many practical problems such as the lack of university teacher resources and teaching equipment. Universities cannot resolve these problems within a short period of time, but just utilize existing teaching equipment and previous teaching mode to accomplish the music theory teaching task; concretely, they generally adopt the sweeping teaching approach to impart the piano theory knowledge to students, rather than consider the practical requirements of piano curriculums; the teaching mode of vocal music course has seriously violated the principle of individualized teaching, and the same teaching method adopted for all the students has obstructed the effective improvement of teaching quality. Besides, the enrollment expansion plan of universities has also resulted in quality problem of music student sources. The expansion of enrollment scale has greatly reduced the difficulty for students to be admitted to higher conservatories, and most examinees need just a few months to enter higher conservatories, which lead to poor comprehensive quality of students enrolled in universities and consequently result in great decrease in teaching quality.

\section{Reform measures for cultivation mode of application-oriented talents majoring in music in local undergraduate universities}

\section{Formulating a rational talent cultivation scheme based on students' ability training requirements}

With the rapid development in various aspects of the society, higher requirements are raised for the talent cultivation scheme; meanwhile, the essential attributes and long-term objectives of application-oriented talent cultivation have also changed correspondingly, and have been deeply branded with the imprint of age. The talent cultivation scheme of local undergraduate universities pays high attention to the cultivation of application-oriented talents; therefore, it is required to attach importance to its rationality when preparing the talent cultivation scheme and to formulate clear cultivation objectives based on students' different ability levels. The scope of student ability test includes each student's specialty quality ability, personal reproducibility ability, innovation ability, professional post group ability, and other comprehensive abilities. When altering the application-oriented talent cultivation scheme, it is required to fully consider the actual situations of local undergraduate universities; when implementing the cultivation scheme, it is necessary to attach importance to the school-running philosophies of "survival and development on the basis of quality", the positioning standards of "being based on locality, facing grass roots, and serving local economic and cultural construction", the school-running characteristics of "strong specialty, powerful foundation, and wide development" and corresponding school-running ideas, so as to strive for achieving the cultivation objectives of such as extensive art knowledge, wide professional skills, high comprehensive quality, strong practical ability, etc. Besides, under the premise of paying attention to enhancing students' own abilities, it is also required to consolidate students' theoretical knowledge learned, cultivate their innovative thinking and spirit, and encourage them to combine the theoretical knowledge with practice, with the purpose of establishing a better platform for the development of 
local culture. Adopting the application-oriented talent cultivation scheme formulated in the new era can not only facilitate the development of rural and urban integration and the construction of socialist culture with Chinese characteristics, but also provide certain theoretical basis for special school running and play a very important significance in the process of practice and school running.

\section{Changing the teaching philosophy and rationally arranging the major courses}

The schooling philosophy of music education will play a decisive role in the current condition and future development prospect of music education major; therefore, selecting a rational schooling philosophy of music education major is very significant for the cultivation of application-oriented music art talents in the new era. In the process of cultivating application-oriented talents of music education major, local universities shall follow the selected school-running philosophy, strive for enhancing students' abilities of accumulating cultural knowledge, urge students to develop a good professional moral sentiment, enhance students' abilities of music art performance, and pay attention to cultivating students' innovative music thought. It is required to rationally arrange major courses based on students' different practical situations, so as to meet the needs of most students. In the aspect of rationally arranging the major courses, it is required to firstly ensure that students can fully learn rick and professional theoretical knowledge and to take reliable measures to establish a perfect knowledge system. $\mathrm{T}$ he specific requirements include: firstly, offer more relevant basic scientific and cultural courses such as literature appreciation, thesis writing, secretarial science, etc., and adjust the setting of different specialized courses; secondly, always pay attention to the dynamic change of music market and then timely adjust the teaching contents of music education based on such change, such as offering different major courses based on the actual needs, and pay attention to combination of major courses and music education practice. It is also possible to offer corresponding optional courses while opening some major courses, so as to meet students' demands for music education in a faster and better way.

\section{Attaching importance to practical teaching and cultivating application-oriented talents}

The practical teaching can further consolidate students' theoretical music knowledge, strengthen their deep understanding of theoretical knowledge, and greatly facilitate the cultivation of innovative application-oriented talents necessary for the society, as it applies the theoretical knowledge into practice to facilitate students' understanding of more scientific learning methods and enhancement of their own abilities. The major of music art in newly established universities shall grasp the relationship between theory and practice, periodically organize students for relevant professional trainings to prepare for achieving the cultivation of "innovative" and "application-oriented" talents, vigorously establish the "all-round" talent training institutions, actively adopt the theory-practice combined teaching mode, timely update the teaching methods and improve the teaching contents based on the practical needs, greatly enhance the teacher force, strive for exploring diversified practice channels, strengthen the supervision on the whole process, positively organize students for rehearsal of different artistic performance forms, and pay attention to specific practices such as bringing culture to the countryside, communication on in-campus and off-campus artist performance experience, exhibition of teaching achievements, etc., so as to make students more familiarized with the requirements on professional skills, establish a reliable culture construction system, and consequently enhance students' abilities of comprehensively utilizing the knowledge learned. In the context of paying attention to enhancing the national cultural soft power, the music majors of newly established undergraduate universities will encounter different problems in the future, however, it is also a rare opportunity for the music education of newly established universities to toughen themselves; so these universities shall accept such severe test.

\section{Formulating the rational enrollment plan and enhancing the quality of student sources}

The scale of music education resources of local undergraduate universities is increasingly expanding, and their enrollment scale shall be naturally expanded; however, while paying attention to the enrollment number, the music education of local undergraduate universities has ignored its possible influence on their teaching quality. For such a problem, local undergraduate universities shall make a deep analysis on internal relation between enrollment number and teaching quality, and then take corresponding measures to resolve the problems occurred. The music education of local 
undergraduate universities shall change relevant teaching methods based on the teaching demands of the current stage, in which an important point is to adopt the multi-way and multi-level selection principles to select excellent students; besides, the test conent of music education in universities shall lay emphasis on checking students' professional skill level, internal potential in this discipline, their comprehensive quality, etc., which shall be also the main content to decide whether the students will be enrolled. After resolving the problems resulted from enrollment expansion, the music education of local universities must consider the specific optimized scheme for this discipline; in order to improve the teaching quality after enrollment expansion, the curriculum arrangement must be adjusted rationally. Although it is theoretically required to do so, it cannot be said that the large-class teaching method previously adopted for music education is unscientific. In recent years, we can see, from the results of relevant investigations carried out in most music universities in Guangdong Province and from the results of subsequent analysis, that the large-class teaching mode adopted in the professional music teaching process plays a practical role, namely, the large-class teaching method adopted for music major also has the practicability and operability to some extent, as long as we can grasp the skills.

\section{Conclusion}

In general, in order to cultivate professional muisc talents, we need transform the teaching mode, change teachers' traditional teaching philosophies, take the market demand as the guiding ideology, and pay attention to the talent cultivation methods. Meanwhile, we need to strengthen the development of teachers' innovative thought, adopt advanced teaching methods to stimulate students' thirst for knowledge, enrich the classroom teaching content, enhance students' imagination and facilitate their moral, intellectual and physical development, and try to offer special and professional skills, so as to make them grasp more skills and techniques and become all-round talents in music major.

\section{References}

[1] Ji Mingming, Thought on Cultivation of Innovative Talents Majoring in Music Education in Normal Universities. China Adult Education, 2010, (19).

[2] Chen Yanxiang, Discussion on Cultivation of Application-oriented Talents Majoring in Music Education. Journal of Chongqing University of Science and Technology (Social Science Edition), 2011, (13).

[3] Wu Yan, Inspiration of Foreign Community Music Education to Facilitate Business Establishment by College Students of Music Major. Continue Education Research, 2011, (02).

[4] Zhang Tao, Analysis and Thought on Current Situation of Music Education in Normal Universities. Journal of Guizhou University: Artist Edition, 2009, (02). 